\title{
Power Flow and Static Voltage Stability Improvement using TCSC and SVC
}

\author{
Avnish Kumar \\ Gaur \\ A.F.S.E.T. \\ Faridabad, India
}

\author{
Aziz Ahmed \\ A.F.S.E.T. \\ Faridabad, India
}

\author{
Tanmoy Deb \\ KIIT College of \\ Engineering \\ Gurgaon, India
}

\author{
Ravindra Pratap \\ Singh \\ BDES Group of \\ Institutions \\ Faridabad, India
}

\begin{abstract}
Restructuring of electricity markets is adding new complexities due to the presence of large number of market players. The congestion in transmission lines is one such effect born out of restructuring exercise.

Mitigation of congestion was easier in vertically integrated utilities but this is more complex in restructured system. This paper examines the effect of TCSC and SVC in improvement of power flow and voltage stability enhancement in a power network. The proposal has been tested on IEEE-14 bus system.
\end{abstract}

\section{Keywords}

Power flow, static voltage stability, TCSC, SVC

\section{INTRODUCTION}

After restructuring of electricity sector, the power system has undergone a sea change. With environmental factors and right of way issues, building of new transmission lines are hampered. The growing demands in power system due to increase in load, wide load diversity, unplanned power exchanges, open access etc. affects secure and reliable operation of power system. The system also experiences severe overload on certain transmission corridors. Hence, to improve system security, reliability and stability, FACTS (Flexible AC Transmission System) are widely used. TCSC (Thyristor Controlled Series Capacitor) and SVC (Static Var Compensator) are two such power electronic devices which are used to improve power flow and voltage stability of networks.

FACTS devices help to improve system stability \& reliability, damp power system oscillations, improve voltage profile, increase power flow etc. The use of FACT devices not only helps to increase power flow and improve static voltage stability but also defers the need for new transmission line.

This paper investigates the effect of TCSC in enhancing the power flow by varying the line reactance.

SVC is used to improve the profile of voltage of buses and ensure rapid injection of reactive power into the bus.

This paper is organised as follows- section-2 reviews the literature on the subject, section-3 deals with mathematical modelling of TCSC and SVC. Section-4 discusses simulation result \& conclusion is given in section-5.

\section{LITERATURE REVIEW}

The world's first SVC was installed by Tennesee Valley Authority in USA for the improvement of voltage profile. The concept of FACTS devices were proposed by Hingroni et al [1]. These devices- series, shunt and combined series and shunt are thyristor controlled power electronic devices which alters line reactance $(\mathrm{X})$, voltage magnitude $(\mathrm{V})$ \& voltage angle $(\theta)$. SVC is a parallel combination of a capacitor and thyristor controlled reactor. It is used to inject the reactive power into the system thereby controlling voltage profile of buses [2]. Siddiqui and Deb [3] had used SVC to control bus voltage by injecting or absorbing reactive power by varying firing angle of thyristor controlled reactor. Thukaram et al [4] used SVC for voltage stability improvement and determined the rating and location of SVC for optimum gain in power network.

Owlegard et al. [5] had used TCSC to improve power flow in a power network by varying the line reactance. Siddiqui and Deb [6] had used TCSC in restructured electricity markets to reduce line congestion by varying the firing angle of thyristor. It was demonstrated that line reactance is a function of firing angle of thyristor which ultimately regulates power flow in a line.

Cannizarse et al [7] had used both SVC and TCSC to study voltage collapse phenomenon and had demonstrated their successful use.

\section{MODELLING OF DEVICES 3.1 Modelling of SVC}

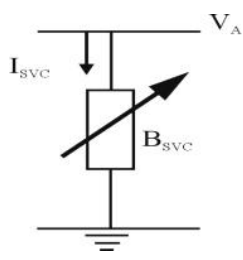

Fig. 3.1 SVC equivalent circuit

The positive sequence susceptance of SVC (BSVC) which consists of inductance $\mathrm{XL}$ and shunt capacitance $\mathrm{XC}$ is given by:

$\mathrm{B}_{\mathrm{SVC}}=\frac{1}{\mathrm{XLXC}}\left[\mathrm{X}_{\mathrm{L}}-\frac{\mathrm{X}_{\mathrm{C}}}{\pi}(2 \pi-2 \alpha)-\frac{\mathrm{X}_{\mathrm{C}}}{\pi} \operatorname{Sin} 2 \alpha\right]$.

Since reactive power drawn by SVC at bus 'A' is given by-

$\mathrm{Q}_{\mathrm{SVC}}=-\mathrm{VA}_{\mathrm{A}}^{2} \mathrm{~B}_{\mathrm{SVC}}$

Hence, substituting eq.(1) in above equation, (2) reactive power at bus ' $A$ ' is given by-

$Q_{A}=\frac{-V_{A}^{2}}{X_{L} X_{C}}\left[X_{L}-\frac{X_{C}}{\pi}(2 \pi-2 \alpha)-\frac{X_{C}}{\pi} \operatorname{Sin} 2 \alpha\right] \ldots$

The linearized SVC equation is given by 


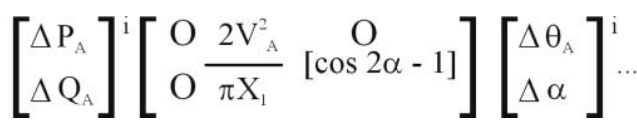

At the end of each iteration (i), firing angle ( $\alpha$ ) is updated as per following

$\alpha^{i+1}=\alpha^{i-1}+\alpha^{i}$

\subsection{Modelling of TCSC}

A TCSC consists of a fixed capacitor in parallel with a thyristor controlled reactor.

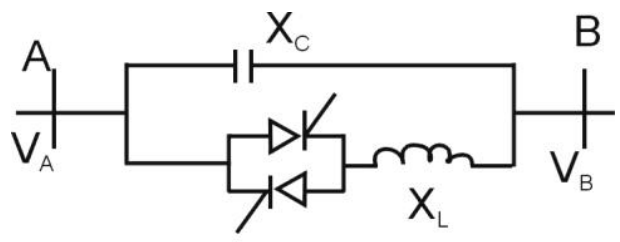

Fig. 3.2 TCSC Model

The equivalent reactance of TCSC model in

Fig. 3.2 is given by [6]

$\mathrm{XC}=-\mathrm{XC}+\mathrm{C} 1[2 \pi-2 \alpha+\operatorname{Sin}(2 \pi-2 \alpha)]-\mathrm{C} 2 \operatorname{Cos} 2(\pi-\alpha)[\omega$ $\tan (\omega \pi-\omega \alpha)-\tan (\pi-\alpha)] \ldots$.

Where

$$
\begin{aligned}
C_{1} & =\frac{X_{C}+X_{L C}}{\pi} \\
C_{2} & =\frac{4 X_{L C}^{2}}{X_{L L} \pi} \\
X_{L C} & =\frac{X_{L} X_{C}}{X_{C}-X_{L}} \\
\omega & =\sqrt{\frac{X_{C}}{X_{L}}}
\end{aligned}
$$

The active and reactive power at bus ' $\mathrm{A}$ ' are :

$\mathrm{PA}=\mathrm{VA} \mathrm{VBBAB} \sin (\theta \mathrm{A}-\theta \mathrm{B})$

$\mathrm{QA}=\mathrm{V} 2 \mathrm{~A} B \mathrm{BB}-\mathrm{VA} \mathrm{VB} \mathrm{BAB} \cos (\theta \mathrm{A}-\theta \mathrm{B})$.

Where

$\mathrm{BAA}=-\mathrm{BAB}=\mathrm{BTCSC}$

The linearized power equations for the case when TCSC controls active power flow from bus A to bus B at a specified value is given by

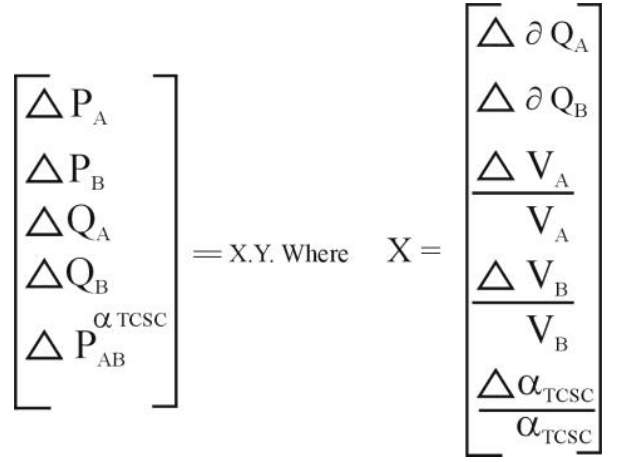

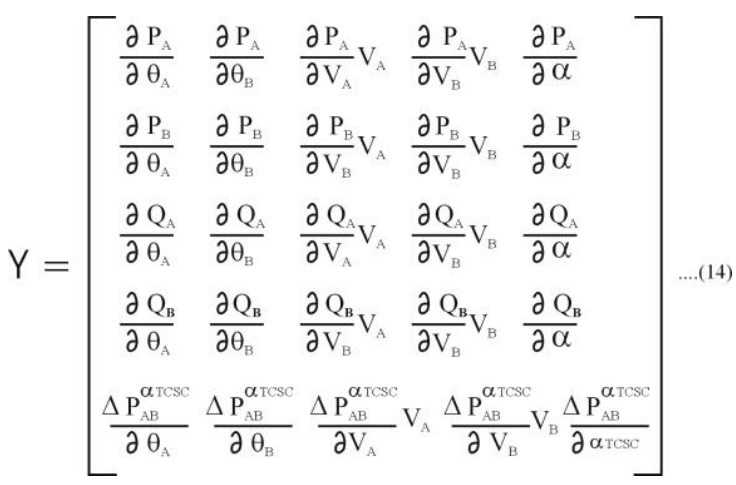

$\Delta \mathrm{P}_{\mathrm{AB}}^{\alpha \mathrm{TCSC}}$ is given by

$\Delta \mathrm{P}_{\mathrm{AB}}^{\alpha \mathrm{TCSC}}=\mathrm{P}_{\mathrm{AB}}^{\mathrm{reg}}-\mathrm{P}_{\mathrm{AB}}^{\alpha \text { TCSC.cal }}$

This is active power mismatch and $\Delta \boldsymbol{\alpha}_{\mathrm{TCSC}}$ is given by

$$
\Delta \alpha \operatorname{TCSC}=\alpha_{\mathrm{TCSC}}^{i+1}-\alpha_{\mathrm{TCSC}}^{i}
$$

\section{RESULTS AND DISCUSSION}

IEEE-14 bus system is taken as test case. Load flow is carried out on IEEE-14 bus system using Newton Raphson method. SVC is incorporated into Newton Raphson load flow algorithm.

The base case result shows that voltage in the bus number -5 , $6,7,9,10,11,12,13$ and 14 are below 1 pu. So, SVC is connected to these buses to improve voltage of the buses to 1 pu. This is shown in table 4.1.

It is seen that voltage of the buses are improved to 1 per unit with corresponding reactive power and firing angle are shown. Since the bus voltages are less than 1 pu hence reactive power is injected into the buses (shown by - sign). For example, in bus 9 , before connection of SVC, bus voltage is $0.9595 \mathrm{pu}$ which after connection of SVC becomes 1 pu with a firing angle of 135.91 degree $\&$ reactive power injection of 0.3383 pu.

To test the effectiveness of SVC with varying load. The load on bus is increased by $20 \%$ which results in further fall in bus voltages. Now, with SVC connected to the bus, voltage is restored to $1 \mathrm{pu}$ again. This is shown in table 4.2. Hence, it is seen that SVC improves the voltage stability of the bus (Fig. 4.1). Table 4.3 shows improvement in power flow using TCSC. TCSC has been connected to branch 2-4. The base case power flow (without TCSC) is 0.5554 pu.. After connection of TCSC to this branch, power flow is increased to $0.6109 \mathrm{pu}$ with a firing angle of 146.9 degree and TCSC reactance of -0.0275 pu. Similarly, in branch 13-14, base case power flow is $0.0567 \mathrm{pu}$ which increases to $0.0623 \mathrm{pu}$ after connection of TCSC to this branch, the corresponding TCSC reactance is $-0.0314 \mathrm{pu}$ with a firing angle of 146.3 degree. Hence, it is seen that TCSC improves active power flow in a branch. (Fig. 4.2).

\section{CONCLUSION}

SVC was implemented on IEEE-14 bus system. It was observed that SVC could improve static voltage stability of the bus. With higher loading, SVC could still improve voltage profile. 
TCSC was implemented on IEEE-14 bus system. It was found that TCSC could increase power flow in a branch even with higher loading.

\section{REFERENCES}

[1] N.G. Hingrorani, L.Gueygi, "FACTS: Concept and technology of flexible a.c. transmission system", IEEE press, 2000.[2] Nang Sabai, Hun Nandar Maung, Thida Win "Voltage control and dynamic performance of transmission system using static Var compensator". World Academy of Sciences, Engg \& Technology, 42, 2008.

[2] Anwar S. Siddiqui, Tanmoy Deb, "Voltage stability enhancement through static var compensator", International J. of Scientific and Engineering Research, vol. 4, issue-2, Feb-2013
[3] D. Thukaram, A. Loni, "Selection of static Var compensator location \& size for system voltage stability improvement", Electrical Power System Research, 54(2). Pp. 139-250, 2000.

[4] A. Owlegard et al, "Improvement of transmission capacity by thyristor controlled series capacitor", IEEE PAS, vol. 10, no. 8, pp. 3930-3939, 1981.

[5] A.S. Siddiqui, Tanmoy Deb, "Congestion management in restructured electricity market using TCSC", International J. of Electrical \& Electronics Engineering Research, vol. 3, issue-2, June-2013, pp. 87-92.

[6] C.A. Cannizares, Z.T Faur, "Analysis of SVC and TCSC controlled in voltage collapse", IEEE trans. Power System, vol-14, no. 1, Feb. 1999, pp. 158-165.

Table no. 4.1 Voltage stability improvement using SVC(base case)

\begin{tabular}{|c|c|c|c|c|}
\hline \multirow{2}{*}{ Bus no. } & Bus voltage & \multicolumn{3}{|c|}{ Bus Voltage with SVC } \\
\cline { 3 - 5 } & without svc (pu) & Voltage (pu) & Reactive Power (pu) & Firing Angle (deg) \\
\hline 5 & 0.9974 & 1.0 & -0.1226 & 130.64 \\
\hline 7 & 0.9780 & 1.0 & -0.2615 & 133.93 \\
\hline 9 & 0.9595 & 1.0 & -0.3383 & 135.91 \\
\hline 10 & 0.9563 & 1.0 & -0.2676 & 134.08 \\
\hline 11 & 0.9679 & 1.0 & -0.1732 & 131.79 \\
\hline 12 & 0.9703 & 1.0 & -0.1233 & 130.63 \\
\hline 13 & 0.9642 & 1.0 & -0.2696 & 134.13 \\
\hline 14 & 0.9417 & 1.0 & -0.2398 & 1339 \\
\hline
\end{tabular}

Table no. 4.2 Voltage stability improvement using SVC with $20 \%$ increase in load

\begin{tabular}{|l|l|l|l|l|}
\hline Bus no. & $\begin{array}{l}\text { Voltage at 20\% } \\
\text { increased load (without } \\
\text { SVC) }\end{array}$ & \multicolumn{2}{|l|}{$\mathbf{2 0 \% \text { Increased load with SVC }}$} \\
\cline { 2 - 5 } & Voltage (pu) & Reactive Power (pu) & Firing Angle (deg) \\
\hline 5 & 0.9655 & 1.0 & -0.2675 & 134.08 \\
\hline 7 & 0.9478 & 1.0 & -0.3417 & 136.00 \\
\hline 9 & 0.9198 & 1.0 & -0.4265 & 138.38 \\
\hline 10 & 0.9141 & 1.0 & -0.3349 & 135.82 \\
\hline 11 & 0.9247 & 1.0 & -0.2163 & 132.82 \\
\hline 12 & 0.9242 & 1.0 & -0.1490 & 131.24 \\
\hline 13 & 0.9172 & 1.0 & -0.3297 & 135.68 \\
\hline 14 & 0.8935 & 1.0 & -0.2965 & 134.81 \\
\hline
\end{tabular}

Table 4.3 Power flow improvement using TCSC

\begin{tabular}{|l|l|l|l|l|l|}
\hline \multirow{2}{*}{ S.NO. } & \multicolumn{3}{|c|}{ Base case without TCSC } & \multicolumn{2}{c|}{$\mathbf{1 0 \%}$ increased active power ( with TCSC ) } \\
\cline { 2 - 6 } & \multicolumn{1}{|c|}{ Branch from } & $\begin{array}{c}\text { Base case power } \\
\text { flow (pu) }\end{array}$ & $\begin{array}{c}\text { Active power flow } \\
(\mathbf{p u})\end{array}$ & $\begin{array}{c}\text { TCSC reactance } \\
(\mathbf{p u})\end{array}$ & Firing angle (deg) \\
\hline 1 & $2-4$ & 0.5554 & 0.6109 & -0.0275 & 146.9 \\
\hline 2 & $12-13$ & 0.0168 & 0.0184 & -0.0178 & 150.1 \\
\hline 3 & $13-14$ & 0.0567 & 0.0623 & -0.0314 & 146.3 \\
\hline 4 & $2-3$ & 0.7433 & 0.8176 & -0.0503 & 144.8 \\
\hline 5 & $2-5$ & 0.4122 & 0.4500 & -0.0241 & 142.9 \\
\hline 6 & $4-5$ & 0.6130 & 0.6743 & -0.0210 & 148.6 \\
\hline
\end{tabular}




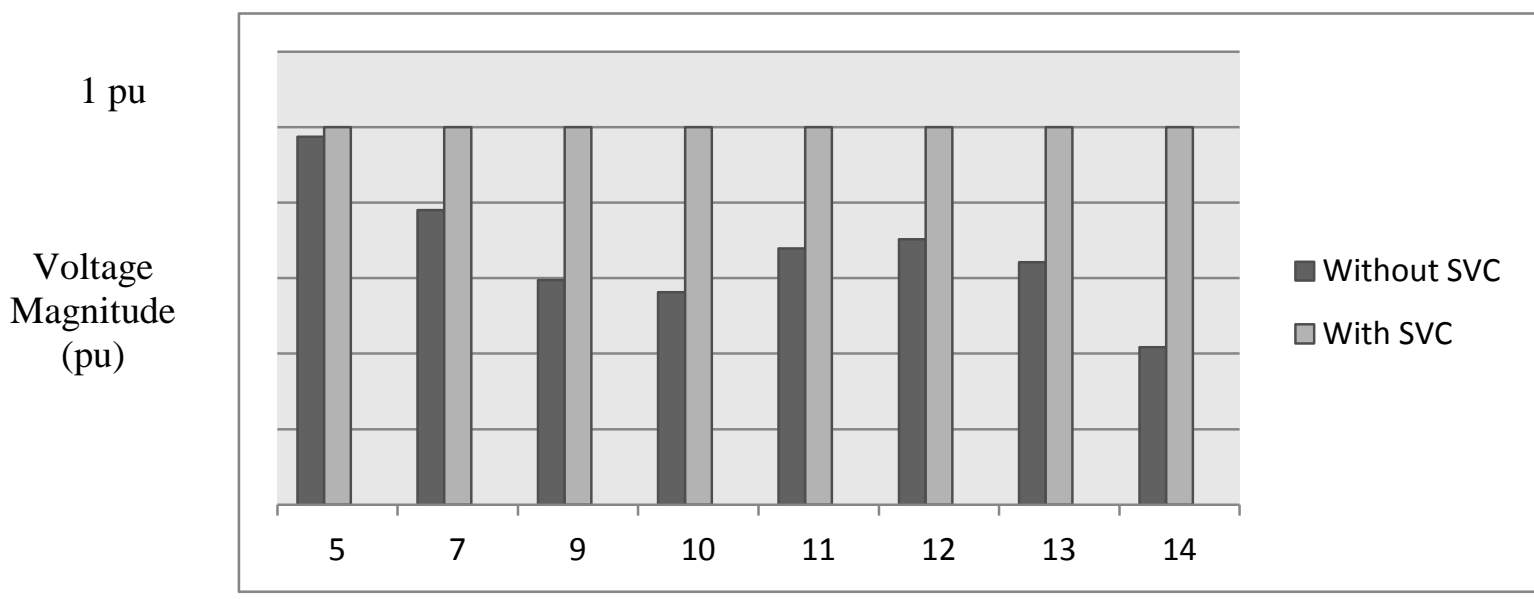

Bus no.

Fig. 4.1 Bus voltage improvement using SVC

Active

Power

Flow

(pu)

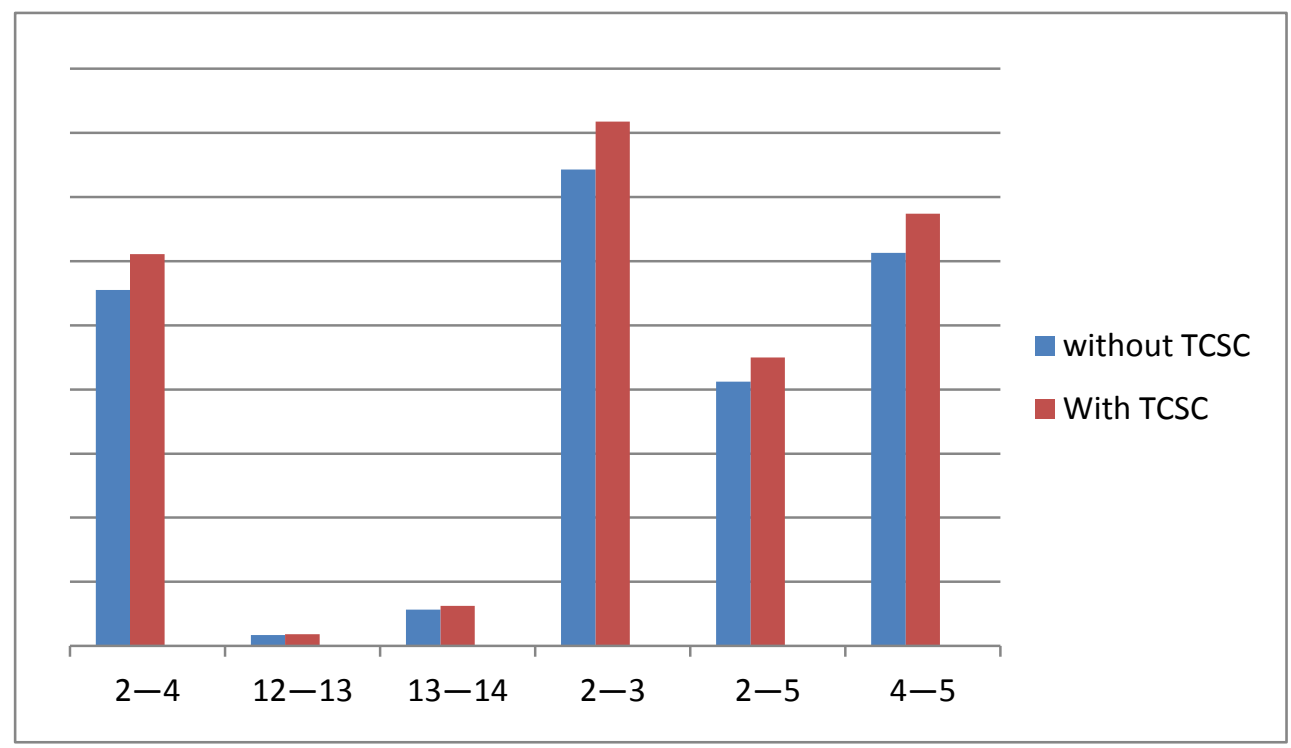

Bus no.

Fig. 4.2 Increased power flow with TCSC 